\title{
Overview of past, present and future Brazilian small satellites missions
}

\begin{abstract}
In the last 6 years, a total of six small satellites where developed and launched in Brazil: NCBR-1 (2014), research on climate and phenomena, such as the SouthAtlantic Anomaly (SAA); AESP-14 (2015), communication failures after problems with the antenna deployment; SERPENS-1 (2015), operated with data collection and communication with a ground station; Tancredo-1 (2017), educational satellite; ITASAT (2018), experiment for amateur radio communications amongst other objectives; and the last one, Floripasat (2019), a continuation of the SERPENS 1model. Showing an increase in production, nine more cubesats launches are planned for 2020 - 2022: Alfa Crux, 14BisSat, NCBR-2, ConnaSat A, ConnaSat B, Garatea, Sport and the VCUB constellation. With a growing national interest in CubeSat platform and variations, a transition from educational and experimental activities to a more demand driven technology production is expected. In 2018 , a joint initiative between the Brazilian Space Agency and Brazil Industrial Development Agency opened the discussion on commercial development of mature technology. At the occasion, in São José dos Campos, the nation's aerospace demands were categorized in earth observation, data gathering, meteorology, communication, GP Sand science missions. The present study explores the goals and status of previous Brazilian CubeSat missions, and of the next nine missions planned for the near future. The objective is to investigate the gap between academic and industrial development with a pragmatic view, giving emphasis to the next steps needed to approximate both sectors and stimulate the country's small satellites production and applications. Furthermore, the analyses should serve as a blueprint for business that plan on engaging in future missions in and applications.
\end{abstract}

\author{
Volume 4 Issue I - 2020 \\ Leonardo JC Souza, 'Victor R Baptista, \\ Rafael P Lôbo,' Danilo Sakay² \\ 'IDEIA SPACE, Portugal \\ ${ }^{2}$ Agência Espacial Brasileira, Brazil
}

Correspondence: Leonardo JC Souza, IDEIA Space, Av. Fontes Pereira de Melo 16, 1050-121 Lisboa, Portugal,

Tel +55 6I 99198-3।52, Email ljcs23@gmail.com

Received: March 13, 2020 | Published: April 28, 2020

Keywords: cubesat, Brazil, constellation, overview, business, analysis

\section{Introduction}

Small satellites are the base on which the New Space is built on. It is allowing countries with no expertise, in matter of space, to access it with cheaper and multi functional satellite buses. By the definition of United Nations Office for Outer Space (UNOOSA), small satellites can be split in the following categories ${ }^{1}$ by it mass:

a. mini satellites (100 $\mathrm{kg}$ up to $1000 \mathrm{~kg}$ );

b. micro satellites (10 up to $100 \mathrm{~kg}$ ); c. nano satellites (1 $\mathrm{kg}$ up to $10 \mathrm{~kg}$ );

d. pico satellites $(0,1 \mathrm{~kg}$ up to $1 \mathrm{~kg})$;

e. femto satellites (up to $0,1 \mathrm{~kg}$ ).

They are becoming a tendency in the world as it shows in Figure 1. We can see the fast growth of nanosatellite launches in the decade and also predict a growth for the beginning of the next decade. It is not just the overall number that increases, more and more upper middle income countries and lower middle income countries are able to launch their own manufactured small satellites. ${ }^{2,3}$

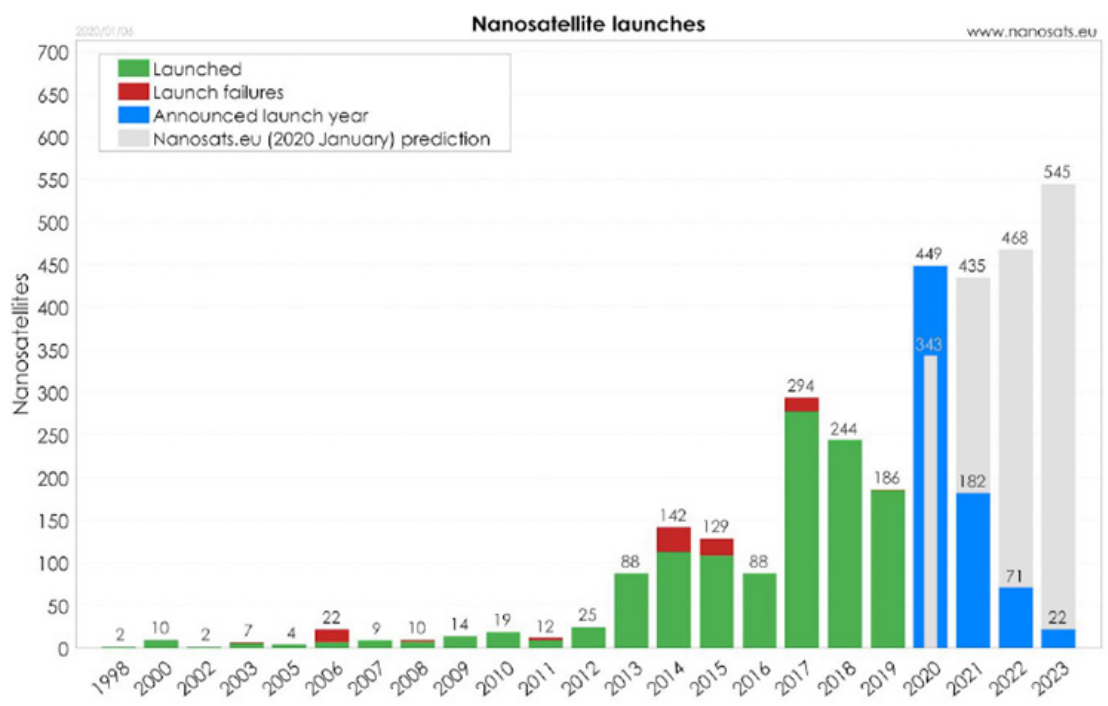

Figure I Nanosatellite launches. 
Although Brazil has become a relevant player amid the upper middle income countries, with programs such as CBERS series and Amazonia Mission for earth observation mission and SCD series for data collecting, new space technologies urge its adaptation from big satellites to small satellite technologies. As the National Institute of Space Research (INPE) cement the Integration and Test Laboratory facility, it enables the development of new business opportunities and Space-tech. ${ }^{4-7}$ The first small satellite made in Brazil was built in the beginning of the 2000's, and only 7 were launched ever since, pairing with the number of big satellites launched in the same period. So this paper brings an overview of those launched missions, to understand the path that Brazil made so far and also of the missions not launched yet, to understand the needs in development to commercial by analyzing the futures claimed space Launch by Brazilian satellite initiatives.

\section{Overview of the seven Brazilian smallsats}

The seven Brazilian small satellites launched are UNOSAT-1, AESP-14, Tancredo-1, NCBR-1, SERPENS, ITASAT and FLORIPASAT.

\section{UNOSAT-}

The satellite's name is an acronym for "Undergraduate Orbital Student Satellite". It was built by students from the University of North Paraná (UNOPAR) and some students from the Stadual University of Londrina. Sadly, the project could not be tested in space because its launching vehicle (VLS-1) exploded days before the launch date. UNOSAT was on board of the rocket along with another Brazilian satellite. ${ }^{9}$ The project idea was to describe a Low Orbit (LEO) at $750 \mathrm{~km}$ and inclination of 15 degrees and transmit regular voice messages to Earth. Besides its mission, UNOSAT would also transmit the solar panels, batteries and CPU temperatures, acceleration and the batteries voltage.

\section{AESP-I 4}

It was built by graduating and post graduating students of Institute of Aeronautics Technologies (ITA) beginning in 2010 and launching in 2015. It was the first cubesat produced and launched by a Brazilian initiative and it was made of 1unity (1U). It had its financial support from Brazilian Space Agency (AEB) and National Council for Scientific and Technological Development (CNPq) costing total of 400 thousand Reais without the launching included. It was carrying an UHF modem to transmit messages associated to Brazilian scientists and also had an experiment for radioamatore, which would transmit randomly 100 sequences of messages. It was planned to have 3 months lifetime in space but when launched the antennas did not open.

\section{TANCREDO-I}

The project was built by 10 to 15 year old students from public school and led by their mathematics teacher Cândido Moura. It was a 650 grams satellite with dimensions not bigger than a soda can. Tancredo- 1 took years to be made and launched from the International Space Station using the Japanese Kibo launcher. It had two payloads, the first one was a message recorded in English and Portuguese by one of the students and the other one was an experiment about bubble formation on Earth's ionosphere. The little satellite was in orbit for 9 months and is considered the first satellite to be built and launched by students that young.

\section{NCBR-}

Launched in 2014, the NCBR-1 Cubesat was an experiment to qualify miniaturized electronics circuits and integrated circuits monitor the geomagnetic conditions of Earth's surface over the
South Atlantic Anomaly and to test an ionic electro jet. The project was idealized by INPE and built in partnership with UFSM (Federal University of Santa Maria). The most interesting thing about this cubesat is that it is still operating until the date this article was written, totalizing 2057 days in space.

\section{SERPENS- I}

This project was Brazil's first $3 U$ cubesat to be made. It was a cooperation between Brazilian Space Agency, University of Brasilia, Federal University of Santa Catarina, Federal University of Minas Gerais, Federal University of ABC, Institute Fluminense, Morehead University, University of Vigo, University of Sapienza and CalPoly. The mission was divided in two, sector " $\mathrm{A}$ ', an ionospheric experiment and sector "B" which was a HUMSAT payload transponder.

\section{ITASAT- I}

The first satellite to use a $100 \%$ Brazilian ADCS Brazilian had two payloads, a commercial camera with resolution of 80 meters per pixel and a communication experiment for the radioamator community. It was also the first $6 \mathrm{U}$ cubesat made in Brazil. It took 9 years from its conception until the launch date (2009-2018), but in the meantime, ITASAT had a redesign of the project in 2013 which gave the team developing it a better direction to follow.

\section{FLORIPASAT}

This satellite was the last one launched by Brazil. It is a $1 \mathrm{U}$ cubesat with a communication mission that is planned to endure for two years. It was made by graduation and post graduation students from Federal University of Santa Catarina, of courses like Electric, Electronics, Aerospace and Mechanical Engineering. Floripasat is the first Brazilian cubesat to transmit using NGH am protocol (Table 1). ${ }^{10-15}$

Table I Brazilian small satellites general specifications

\begin{tabular}{|c|c|c|c|c|}
\hline Satellite & Space bus & Weight & Orbit & Mission \\
\hline UNOSAT-I & Own bus & $8.83 \mathrm{Kg}$ & LEO & Communication \\
\hline AESP-I4 & IU Cubesat & $0.7 \mathrm{Kg}$ & LEO & Communication \\
\hline TANCREDO-I & Tubesat & $0.65 \mathrm{Kg}$ & LEO & $\begin{array}{l}\text { Communication } \\
\text { and Scientific } \\
\text { Experiments }\end{array}$ \\
\hline NCBR-I & IU Cubesat & $\mathrm{I} \mathrm{Kg}$ & SSO & $\begin{array}{l}\text { Scientific } \\
\text { Experiments }\end{array}$ \\
\hline SERPENS & $3 U$ Cubesat & $3 \mathrm{~K}$ & LEO & $\begin{array}{l}\text { Communication } \\
\text { and Scientific } \\
\text { Experiments }\end{array}$ \\
\hline ITASAT-I & $6 U$ Cubesat & $5.2 \mathrm{Kg}$ & LEO & $\begin{array}{l}\text { Communication } \\
\text { and Earth } \\
\text { Imagery }\end{array}$ \\
\hline FLORIPASAT & IU Cubesat & $1.33 \mathrm{Kg}$ & SSO & Communication \\
\hline
\end{tabular}

\section{Analysis of launched Brazilian smallsats}

Now let's take a deeper look and compare the differences between Brazilian smallsats.

\section{By region}

In this analysis it is not considered the production of SERPENS because itwas cooperation between several states from Brazil and other countries, so this would divert the data. So, with only 6 launched small satellites considered, it is possible to list from where each smallsat was produced, as it follows on Figure 2. 


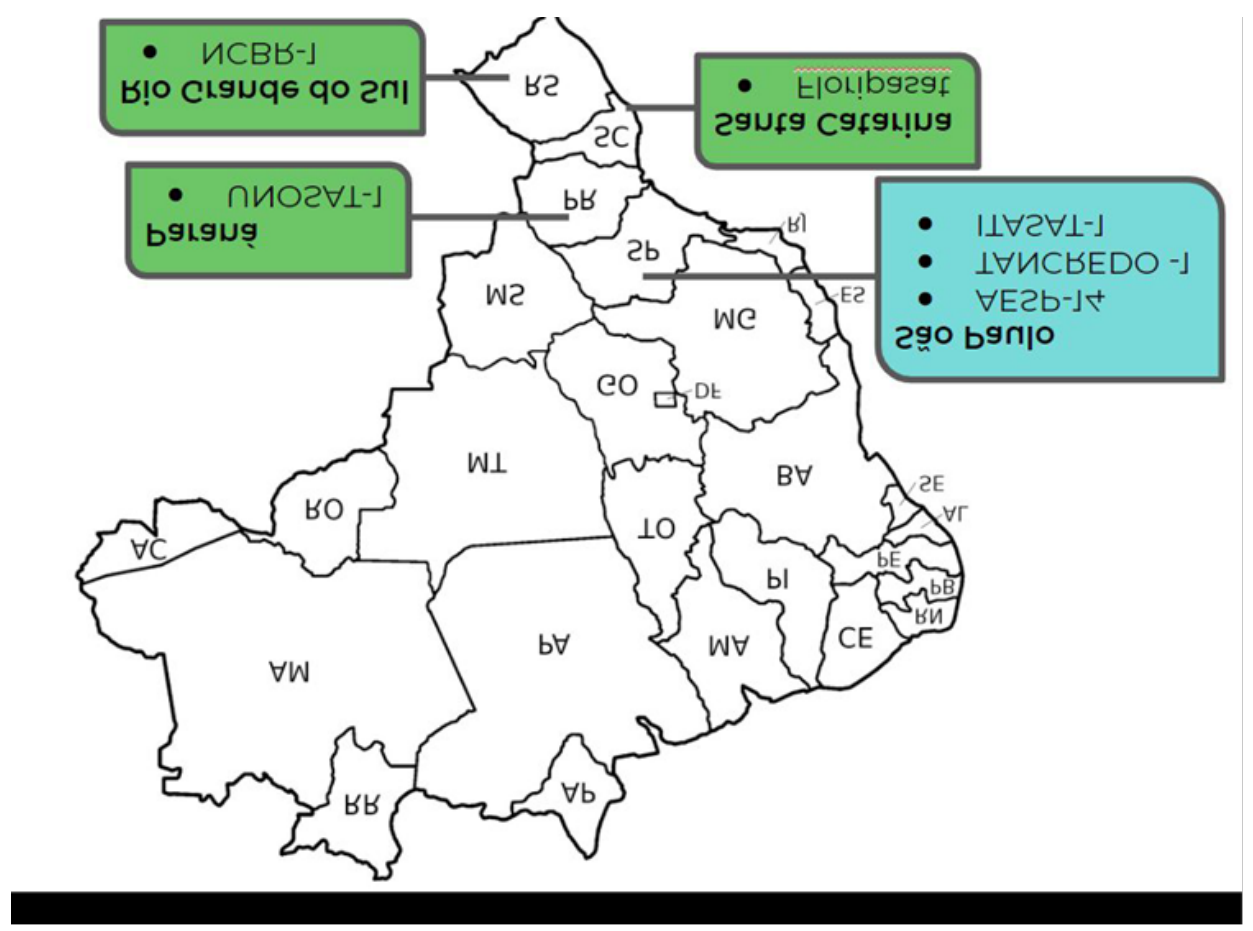

Figure 2 Small satellites by production region (without SERPENS).

In a country as big as Brazil, it is alarming the concentration of the production of launched Smallsats. São Paulo produced three cubesats and the south region of Brazil produced the other three. From this, it is possible to assume two possibilities: either the Brazilian smallsat production is concentrated on southern states, or the production is nationally wide but only the southern smallsats were launched so far. A third possibility, and more reasonable one, is that the smallsat production began in Brazil's southern states and it is now spreading across the country. But to conclude what is the main reason for such discrepancy, it is needed to analyze the future missions.

\section{By timeline}

The first small satellite produced in Brazil by an institution was in 2000, when the University of North Paraná began the UNOSAT project. It took 3 years to be produced and launched, but unfortunately, it did not go to space because of its launcher explosion. After that incident, it took 11 years until the next launch (NCBR-1), even though its project began in 2005. Between 2014 and 2019, Brazil launched a total of 6 nanosatellites, more than one per year (Figure 3).

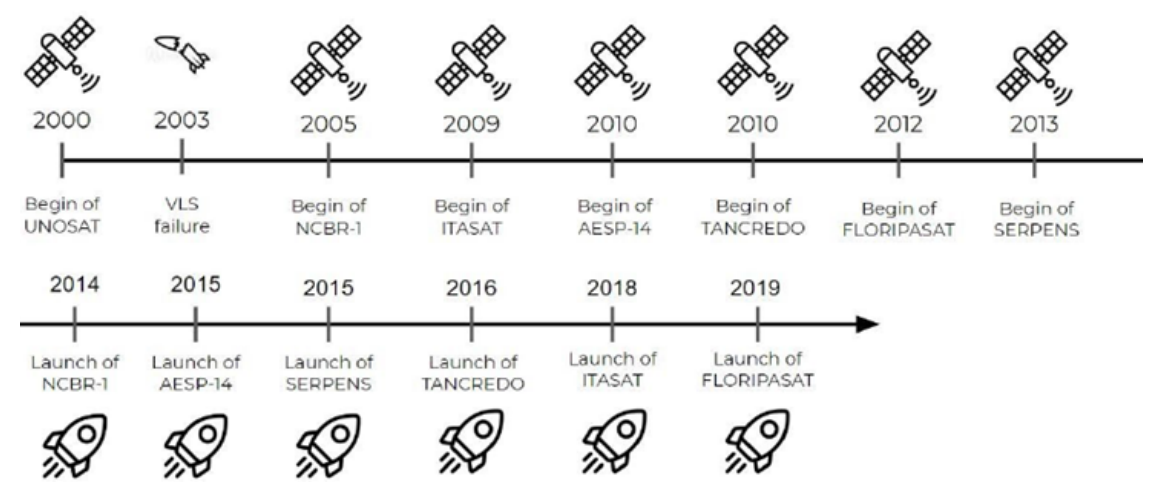

Figure 3 Small satellites in production and launch timeline.

This is a good number considering Brazil's background, but it is not when compared to worldwide launches. In this same period it was launched approximately 995 nanosatellitesworld wide, in other words, Brazil was responsible for only $0.6 \%$ of world's launches.

\section{By development time}

By a different optics, looking now to the development time, a cubesat takes 18 to 24 months for commercial cubesat production, and for universitary ones, it can take twice as long. Taking the figure 33 timeline as parameter, Brazil is far from reaching this number, since it takes on average 6.8 years to develop and launch a cubesat. For this, there are two main possibilities we can assume: either the Universities take too long to develop the satellite because the lack of Cubesat experienced professors in the country; or, most likely, because of the inexistence of a Brazilian launch vehicle, it takes too long to schedule a launch, since it needs to fit into another country's launching window. 


\section{By type}

Of 7 smallsats Brazil has launched, 6 of them have at least one payload focused with communication experiments, and only one smallsat, NCBR-1 is totally focused on scientific experimentation. The last 2 smallsats launched, ITASAT and FLORIPASAT, have used knowledge from previous Brazilian missions and managed to develop innovations on the communication experiments. So, analyzing only the past launches, Brazil's ideal next step is to focus its missions on experiments and commercial applications for smallsats.

\section{Future cubesats preview}

The satellites data that are included on this paper and that are not yet launched were taken from public sources, so any small satellite production that is confidential or are commercially under sigil are not included in this analysis. Brazil intends to launch eleven cubesats between 2020 and 2022, even though some development teams have not yet defined the due date to launch. In Table 2, it is possible to see the preview of those satellites and their situation.

Table 2 Brazilian not launched small satellites general specifications

\begin{tabular}{llllll}
\hline Satellite & Space bus & Expected Launch & Orbit & Mission & $\begin{array}{l}\text { Beginning of the } \\
\text { Project }\end{array}$ \\
\hline Alfa Crux & IU Cubesat & 2021 & LEO or SSO & Communication and loT & 2020 \\
I4-BiSat & 2U Cubesat & Not Defined & LEO or SSO & $\begin{array}{l}\text { Communication and Atmospheric } \\
\text { Measurements }\end{array}$ & 2013 \\
SACODE & 3U Cubesat & 2021 & LEO or SSO & $\begin{array}{l}\text { Scientific Experiments and Atmospheric } \\
\text { Measurements }\end{array}$ & 2017 \\
ConaSat I and 2 & 8U Cubesat & Not Defined & LEO or SSO & Communication and Atmospheric & 2011 \\
Sport & 6U Cubesat & 2020 & Measurements & 2019 \\
Garatea & 6U Cubesat & 2022 & Scientific Experiments & 2018 \\
VCUB & 6U Cubesat & 2021 & Moon Orbit & Scientific Experiments & 2018 \\
NCBR-2 & $2 U$ Cubesat & 2020 & LEO or SSO & Earth Imagery & 2017 \\
Cron-I & $2 U$ Cubesat & 2020 & LEO or SSO & Scientific Experiments & 2014 \\
I4-BISSAT & Own Bus & Not Defined & SSO & Communication & 2004 \\
\hline
\end{tabular}

\section{Brazilian small satellites future missions analysis}

With the past, present and future small satellites data, it is possible to enhance the previous analysis done on topic 3. Starting with the region analysis, the future projects are also centered on the south and southeast regions of the country, with exception of the alfa crux project that is managed by a professor from the center region (Brasília) and Sacode and ConaSat projects, that are being developed on the northeast region. So it is possible to see the production centered on the south and southeast region of the country, but is also possible to see that other parts of Brazil are starting to develop space technologies. Analyzing the development time, it is possible to see that some projects plan to develop and launch their cansat in 2 to 3 years, but there are some projects that have 9 and 16 years of development. Unfortunately the average time is still bigger than 6 years. Which means Brazil will not, in a near future, produce cubesats with average time of the international market. Analyzing the payload promised on the future missions, it is notable that the focus on communication experiments decreased, and now, the missions are focusing on scientific experimentation, which makes sense since most of them are made in universities, and they are also focusing on some commercial usages. For example, the VCUB project aims at the Earth Observation market and will use a camera as the cubesat payload.

\section{Conclusion}

With all the analysis made, both for the past and for the future missions, it's visible that Brazil's Small Satellites are evolving.
Demographically speaking, the production is spreading to other regions of the country, which is a good step to build a solid space market. From the view of development time, the number of missions that are in line with the average production time of the international market increased significantly, so it is possible to assume that Brazil's production maturity has increased, even though it doesn't have its own launch vehicle. This assumption is reinforced when it takes on account the future missions payload analysis, since it shows that the cubesat production is aiming either on scientific advances or on commercial production.

\section{Acknowledgments}

This work was only made possible by an individual initiative of four people, students of aerospace engineering, who see the possibility of boosting the Brazilian aerospace market, which is already an international reference. We should be grateful for the performance of fellow participants throughout the work, the University of Brasilia which provided experience within academia, and the Brazilian Space Agency that generated the knowledge we need to be presenting the work.

\section{Conflicts of interest}

Authors declare that there is no conflict of interest.

\section{References}

1. Guidance on Space Object Registration and Frequency Management for Small and Very Small Satellites. UNOOSA; 2015. 
2. UNOSAT report. Gunter Space Page; 2020.

3. Satellites developed in Brazil will be launched later this year. Writing Technological Innovation; 2003.

4. Valle A, Silva B, Soares C. Spatial project management, from sputnik to current projects; 2017.

5. Eduardo F. Mechanical interface between the satellite and the miniaturized satellite launcher. Santa Maria; 2018.

6. NanosatCBr-1, operating time; 2020.

7. Dnepr Cluster Mission; 2014.

8. Manea S. CITAR Project: Example of Physics Applied to the Technological Independence of the Country. SBF; 2016.
9. ITA students' nanosatellite arrives at the international space station. Institute of Aeronautical Technology: News; 2014.

10. Brazilian Cubesat successfully launched from the international space station. Institute of Aeronautical Technology: News; 2014.

11. Antenna fails, and Brazilian nanosatellite fails to start operation. Veja; 2016.

12. Brazilian Space Agency, news: ITASAT nanosatellite launched from Vandenbergna California base; 2018.

13. Valdemir C. The ITA Cubesat development and Design. Journal of Aerospace Technology and Management. 2017;9(2):147-156.

14. ITASAT, project description; 2020.

15. FLORIPASAT, project description; 2020. 